\title{
A single-step multiplex quantitative real time polymerase chain reaction assay for hepatitis $\mathrm{C}$ virus genotypes
}

\author{
Akanksha Singh, Dhananjay Singh Mankotia, Mohammad Irshad \\ Clinical Biochemistry Division, Department of Laboratory Medicine, \\ All India Institute of Medical Sciences, New Delhi-110029, India
}

\begin{abstract}
Background and Objectives: The variable response of hepatitis $\mathrm{C}$ virus (HCV) genotypes towards anti-viral treatment requires prior information on the genotype status before planning a therapeutic strategy. Although assays for typing or subtyping of HCV are available, however, a fast and reliable assay system is still needed. The present study was planned to develop a single-step multiplex quantitative real time polymerase chain reaction (qPCR) assay to determine HCV genotypes in patients' sera. Methods: The conserved sequences from 5 UTR, core and NS5b regions of HCV genome were used to design primers and hydrolysis probes labeled with fluorophores. Starting with the standardization of singleplex (qPCR) for each individual HCV-genotype, the experimental conditions were finally optimized for the development of multiplex assay. The sensitivity and specificity were assessed both for singleplex and multiplex assays. Using the template concentration of $10^{2}$ copies per microliter, the value of quantification cycle $(\mathrm{Cq})$ and the limit of detection (LOD) were also compared for both singleplex and multiplex assays. Similarly, the merit of multiplex assay was also compared with sequence analysis and restriction fragment length polymorphism (RFLP) techniques used for HCV genotyping. In order to find the application of multiplex qPCR assay, it was used for genotyping in a panel of 98 sera positive for HCV RNA after screening a total number of 239 patients with various liver diseases. Results: The results demonstrated the presence of genotype 1 in 26 of $98(26.53 \%)$ sera, genotype 3 in 65 (66.32\%) and genotype 4 in $2(2.04 \%)$ sera samples, respectively. One sample showed mixed infection of genotype 1 and 3 . Five samples could not show the presence of any genotype. Genotypes 2, 5 and 6 could not be detected in these sera samples. The analysis of sera by singleplex and RFLP indicated the results of multiplex to be comparable with singleplex and with clear merit of multiplex over RFLP. In addition, the results of multiplex assay were also found to be comparable with those from sequence analysis. The sensitivity, specificity, $\mathrm{Cq}$ values and LOD values were compared and found to be closely associated both for singleplex and multiplex assays. Conclusion: The multiplex qPCR assay was found to be a fast, specific and sensitive method that can be used as a technique of choice for HCV genotyping in all routine laboratories.
\end{abstract}

Key words: real time PCR, hepatitis C virus, genotyping, multiplex PCR, liver diseases

\begin{tabular}{|c|}
\hline Access this article online \\
\hline $\begin{array}{l}\text { Website: } \\
\text { www.intern-med.com }\end{array}$ \\
\hline $\begin{array}{l}\text { DOI: } \\
\text { 10.1515/jim-2017-0010 }\end{array}$ \\
\hline Quick Response Code: \\
\hline 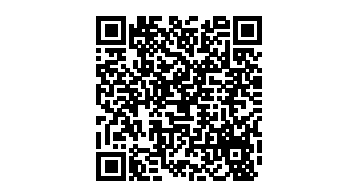 \\
\hline
\end{tabular}

Address for Correspondence: Clinical Biochemistry Division,

Department of Laboratory Medicine,

All India Institute of Medical Sciences,

Ansari Nagar

New Delhi 110029, India

Email: drirshad54@yahoo.com

\section{INTRODUCTION}

Hepatitis C virus (HCV) infection is a serious global health problem infecting 3-4 million people each year. ${ }^{[1]} \mathrm{HCV}$ infection presents both as asymptomatic as well as symptomatic infection. A high proportion of patients infected with HCV develop chronic liver diseases that result in cirrhosis of liver and hepatocellular carcinoma (HCC) in later stage. HCV infection is an indication for liver transplant all over the world. ${ }^{[2]}$ Patients with HCV usually show a poor response to antiviral therapy with a high relapse rate of $\mathrm{HCV}$ infection after discontinuation of therapy. HCV is an RNA virus and belongs to genus Hepacivirus family Flaviviridae. It was first characterized by 
Choo et al. in 1989. ${ }^{[3]}$ Its genome consists of $9.6 \mathrm{~kb}$ singlestranded RNA of positive polarity and an open reading frame of 9033 to 9099 nucleotide flanked by a highly conserved $5^{\prime}$ and $3^{\prime}$ noncoding region (NCR). ${ }^{[4]}$

HCV genome appears as heterogeneous population of different quasi-species that have been categorized into at least six genotypes and more than 100 subgenotypes or isotypes. The presence of HCV genotypes in human population has special significance in terms of the differential response of patients to antiviral treatment. ${ }^{[5]}$ It has been shown that the efficiency of treatment is largely influenced by virus genotypes in addition to several other biological parameters. This aspect of HCV appeals to the necessity of prior knowledge and information on genotyping status of patients before planning the antiviral treatment. For this, there is a need to develop a fast, sensitive and economic assay to determine the genotype status in patients infected with HCV.

The first type-specific genotyping assay was described by Okamoto $e^{~ a l}{ }^{\left[{ }^{[6]}\right.}$ The sequencing of different sub-genomic regions of HCV genome was often used as a gold standard method for genotyping. ${ }^{[7]}$ Analysis of the samples from different parts of the world using sequencing of additional genomic areas like 5' UTR, envelope, and NS5 regions of HCV genome could identify genotypes 3, 4, 5 and 6. Other methods of genotyping include serotyping, ${ }^{[8]} \mathrm{RFLP},{ }^{[9,10]}$ type-specific polymerase chain reaction (PCR) ${ }^{[1]]}$ and hybridization based line probe assay (LiPA). ${ }^{[12]}$ Recently, some methods involved the use of single-step real-time reverse transcription-PCR (RT-PCR) with target-specific TaqMan probe. ${ }^{[13,14]}$ However, all these existing techniques for HCV genotyping are time consuming and quite expensive. Therefore, it appears worth to attempt other regions for standardization of new assays.

The present study was designed to develop a single step quantitative real time PCR (qPCR) assay to determine the HCV genotypes in serum by using UTR, core and NS5b region of HCV genome as the target regions. This includes the standardization of a singleplex qPCR for each individual genotype of HCV in the first instance, followed by the development of multiplex qPCR using similar assay conditions. The multiplex assay was used for HCV genotyping in sera samples from patients with different types of liver diseases.

\section{MATERIAL AND METHODS}

\section{Clinical samples}

Blood samples were collected after getting informed consent from a total of 239 patients diagnosed with acute viral hepatitis (AVH), chronic liver diseases (CLD), cirrhosis of liver and hepatocellular carcinoma (HCC) as per prescribed diagnostic criteria. The extraction of nucleic acid from sera followed by reverse-transcription was conducted following standard protocols as described elsewhere..$^{[15]}$ HCV-RNA was detected in sera by a standard PCR protocol using PCR kit from M/s Roche. The study protocol was approved by the Institutional Ethical Committee of All India Institute of Medical Sciences, New Delhi, India.

\section{Database and resources}

Information was downloaded from GenBank, http:// www.ncbi.nlm.nih.gov ${ }_{-}^{[16]}$ Clustal $\mathrm{X}^{[17]}$ was used for multiple sequence alignments and the specificity of sequences were analyzed using BLAST (NCBI). All statistical analyses were carried out with Graph Pad Prism 4.0. The non-commercial software used in this study were: Primer3plus, OligoCalc, Justbio and Genetree.

\section{Nucleotide sequence accession numbers}

The nucleotide sequences used for alignment and designing the primers and probes were obtained from GenBank database with following assigned accession numbers: FJ696533, AF055303, AF011753, AF056007, AJ132996, AY051292, GQ418247, AB444580, AF238485, AF057149, AF238486, L38337, L38330, GQ418265, AF046866, D49374, GQ418285, Y11604, AY921219, EU527920, HM161675, U10235 and U10238.

\section{Designing of primers and probes}

The primers and hydrolysis probes for HCV-RNA detection were obtained from Roche, Germany. These primers and probes were designed using the known sequences of different HCV genotypes with details mentioned in Table $1 \&$ Table 2.

\section{Plasmid control and standard curve}

The standard plasmid DNA construct with gene coding for different genotypes of HCV were cloned into pUC57 vector using the TOPO TA cloning kit (Invitrogen, US). In order to prepare standard curve, serial dilutions of constructs $\left(10^{1}\right.$ to $\left.10^{8}\right)$ were prepared and used as templates in qPCR assay.

\section{Singleplex qPCR for genotyping}

For singleplex qPCR assay in each case, the reaction mix consisted of $10 \mu \mathrm{L}$ of $2 \mathrm{x}$ master mix (Qiagen, Germany), $6 \mathrm{mM} \mathrm{MgCl}, 4 \mu \mathrm{M}$ of forward \& reverse primers each and $4 \mu \mathrm{M}$ of probe. After the addition of $1 \mu \mathrm{L}$ of $\mathrm{cDNA}$, $19 \mu \mathrm{L}$ of reaction mix (for each of the genotypes 1 to 6) was processed by real-time qPCR using the following cycling parameters: $10 \mathrm{~min}$ at $95^{\circ} \mathrm{C} ; 40$ cycles of $15 \mathrm{sec}$ at $95^{\circ} \mathrm{C}, 30 \mathrm{sec}$ at $50^{\circ} \mathrm{C}$ and $30 \mathrm{sec}$ at $60^{\circ} \mathrm{C}$. It was followed by $30 \mathrm{sec}$ at $40^{\circ} \mathrm{C}$ for cooling. In order to assess the effect of mixed genotypes on specificity, standard plasmids were 
Irshad et al.: A single-step multiplex quantitative real time polymerase chain reaction assay for hepatitis $\mathrm{C}$ virus genotypes

\begin{tabular}{llll}
\hline \multicolumn{4}{l}{ Table 1: Target regions and positions on HCV genome used for detection of different genotypes } \\
\hline Genotype & Region & Amplicon size & Position* \\
\hline G1 & UTR & $132 \mathrm{bp}$ & $102-234$ \\
G2 & UTR & $101 \mathrm{bp}$ & $167-268$ \\
G3 & UTR & $137 \mathrm{bp}$ & $218-338$ \\
G4 & Core & $109 \mathrm{bp}$ & $584-693$ \\
G5 & NS5b & $194 \mathrm{bp}$ & $8023-8218$ \\
G6 & UTR & $96 \mathrm{bp}$ & $138-234$ \\
\hline
\end{tabular}

G1-G6 corresponds to genotypes.

UTR and NS5b correspond to un-translated regions and non-structural 5b regions of HCV genome.

*Position in genome was tabulated according to the reference sequences. Ref sequence ID: UTR and core: JQ717260.1, NS5b: AF064490.1

\begin{tabular}{|c|c|c|c|c|c|}
\hline Genotypes & $\begin{array}{l}\text { Primers/ } \\
\text { probes }\end{array}$ & Sequence & Fluorophore & Quencher & $\mathrm{Tm}$ \\
\hline \multirow[t]{3}{*}{$\overline{\text { G1 }}$} & FP & 5' ATAGTGGTCTGCGGAACCGG 3' & - & - & 52.8 \\
\hline & $\mathrm{RP}$ & 5' GCACGCCCAAATCTCCA 3' & - & - & 55.2 \\
\hline & probe & 5' AGGACGACCGGGTCCTTTC 3' & FAM & $\mathrm{BHQ} 1$ & 64.5 \\
\hline \multirow[t]{3}{*}{ G2 } & FP & 5' GGAATTG/ACCGGG/AAAGACT 3' & - & - & 57.3 \\
\hline & $\mathrm{RP}$ & 5' AACCCAACGCTACTCGG 3' & - & - & 57.3 \\
\hline & probe & 5' AACCCACTCTATGCCCGGCC 3' & LCRed 610 & $\mathrm{BHO} 2$ & 63.5 \\
\hline \multirow[t]{3}{*}{ G3 } & FP & 5' ACAACCCGCTCAATA/GCCC 3' & - & - & 58.8 \\
\hline & $\mathrm{RP}$ & 5' TTGCACGGTCTACGAGA 3' & - & - & 52.8 \\
\hline & probe & 5' GAGATCACTAGCCGAGTAGTG 3' & HEX & $\mathrm{BHO} 1$ & 62.6 \\
\hline \multirow[t]{3}{*}{ G4 } & FP & 5' ATGGCCTCTTTACGGTAA 3' & - & - & 51.4 \\
\hline & $\mathrm{RP}$ & 5' ATTGCGGGACCTCCCG 3' & - & - & 56.9 \\
\hline & probe & 5' ACCGTCTTGGGGCCCAAATGAT 3' & LCRed 640 & $\mathrm{BHO} 2$ & 62.1 \\
\hline \multirow[t]{3}{*}{ G5 } & FP & 5' TGCGAGAAGCGGGCAT 3' & - & - & 51.4 \\
\hline & $\mathrm{RP}$ & 5' TCATTATGTCATGTTCGGTA 3' & - & - & 56.9 \\
\hline & probe & 5' ATGGGGCCCTCGTACGGGTTT 3' & LCRed 710 & $\mathrm{BHO} 2$ & 66.5 \\
\hline \multirow[t]{3}{*}{ G6 } & FP & 5' ATAGTGGTCTGCGGAACCGG 3' & - & - & 52.8 \\
\hline & $\mathrm{RP}$ & 5' GCACGCCCAAATCTCCA 3' & - & - & 55.2 \\
\hline & probe & 5' GGTCCTTTCCATTGGATCAAACCC 3' & LCRed 670 & $\mathrm{BHO} 2$ & 64.6 \\
\hline
\end{tabular}

FP: forward primers; RP: reverse primer; Tm: melting temperatures; FAM: 6-fluorescein amidite; HEX: hexachloro fluorescein; LC: LightCycler; BHQ: black hole quencher.

mixed in 1:1 ratio using $10^{8}$ copies $/ \mu \mathrm{L}$ concentrations in different sets of reaction and the PCR was conducted.

\section{Multiplex qPCR for genotyping}

In multiplex qPCR, the reaction mix consisted of $10 \mu \mathrm{L}$ of 2x master mix (Qiagen, Germany), $6 \mathrm{mM} \mathrm{MgCl}_{2}, 4 \mu \mathrm{M}$ of forward \& reverse primers and $4 \mu \mathrm{M}$ of probe for each genotype. $19 \mu \mathrm{L}$ of reaction mix was prepared in two sets: one consisting of genotypes 2, 3, 4 and 5 primer probe mixes and the other consisting of genotypes 1 and 6 primer probe mixes, respectively. After the addition of $1 \mu \mathrm{L}$ of $\mathrm{cDNA}$, qPCR was carried out using the following cycling parameters: $10 \mathrm{~min}$ at $95^{\circ} \mathrm{C} ; 40$ cycles of $15 \mathrm{sec}$ at $95^{\circ} \mathrm{C}, 45 \mathrm{sec}$ at $50^{\circ} \mathrm{C}$; and $45 \mathrm{sec}$ at $60^{\circ} \mathrm{C}$ followed by
$30 \mathrm{sec}$ at $40{ }^{\circ} \mathrm{C}$ for cooling. During the multiplex, each standard plasmid was run in triplicate and the mean value of quantification cycle $(\mathrm{Cq})$ for each genotype was used for comparison between singleplex and multiplex assays.

\section{Genotyping by RFLP and Sequencing}

The genotyping was also conducted by RFLP assay using the method of Chinchai et al. and McOmish et al. for comparison. ${ }^{[18,19]}$ Similarly, genotyping by sequencing method using core region of HCV was conducted commercially by Ocimum Biosolutions Ltd, India. The generated sequences were aligned and analyzed by using Clustal X software and were used for comparing the result from qPCR. 


\section{Statistical analysis}

Quantitative variables were expressed as mean \pm standard deviation $(\mathrm{X} \pm \mathrm{SD})$ and compared by Student's test ( $t$-test). Differences in proportion of qualitative variables were tested by Pearson correlation coefficient value $(r)$. Fisher exact test and a $P$-value $<0.05$ were considered to be significant for the comparison of results. Generalized estimating equations were used to test whether the mean differences between $\mathrm{Cq}$ for the total HCV quantification reaction (quantitative $\mathrm{Cq}$ ) and the individual genotype-specific reactions (genotype $\mathrm{Cq}$ ) were significantly different from zero.

\section{RESULTS}

The current study plan was aimed to standardize a multiplex real time PCR assay to determine the HCV genotypes in sera collected from patients carrying HCV infection. In the first phase, a singleplex real time PCR assay was standardized for each individual genotype including genotype- 1 to genotype- 6 using known standards. This was followed by development of multiplex assay, and then, using it for HCV genotyping in HCV RNA positive sera. For the standardization of singleplex qPCR for each of the six genotypes of HCV, the control plasmid constructs corresponding to different sub-genomic regions of HCV genome (5' UTR, core and NS5b) were synthesized, amplified, gel purified and then used for their recombination in plasmid (pUC57). Subsequently, recombinant plasmids were cloned and used to form standard curve for each genotype to determine the presence and concentration of HCV genotypes in clinical samples. Six standard curves were created using eight serial dilutions of linearized plasmid DNA, representing $10^{1}$ to $10^{8}$ DNA molecules (single stranded), in each case. The curves obtained for control plasmids with slope and y-intercept values are shown in Figure 1.

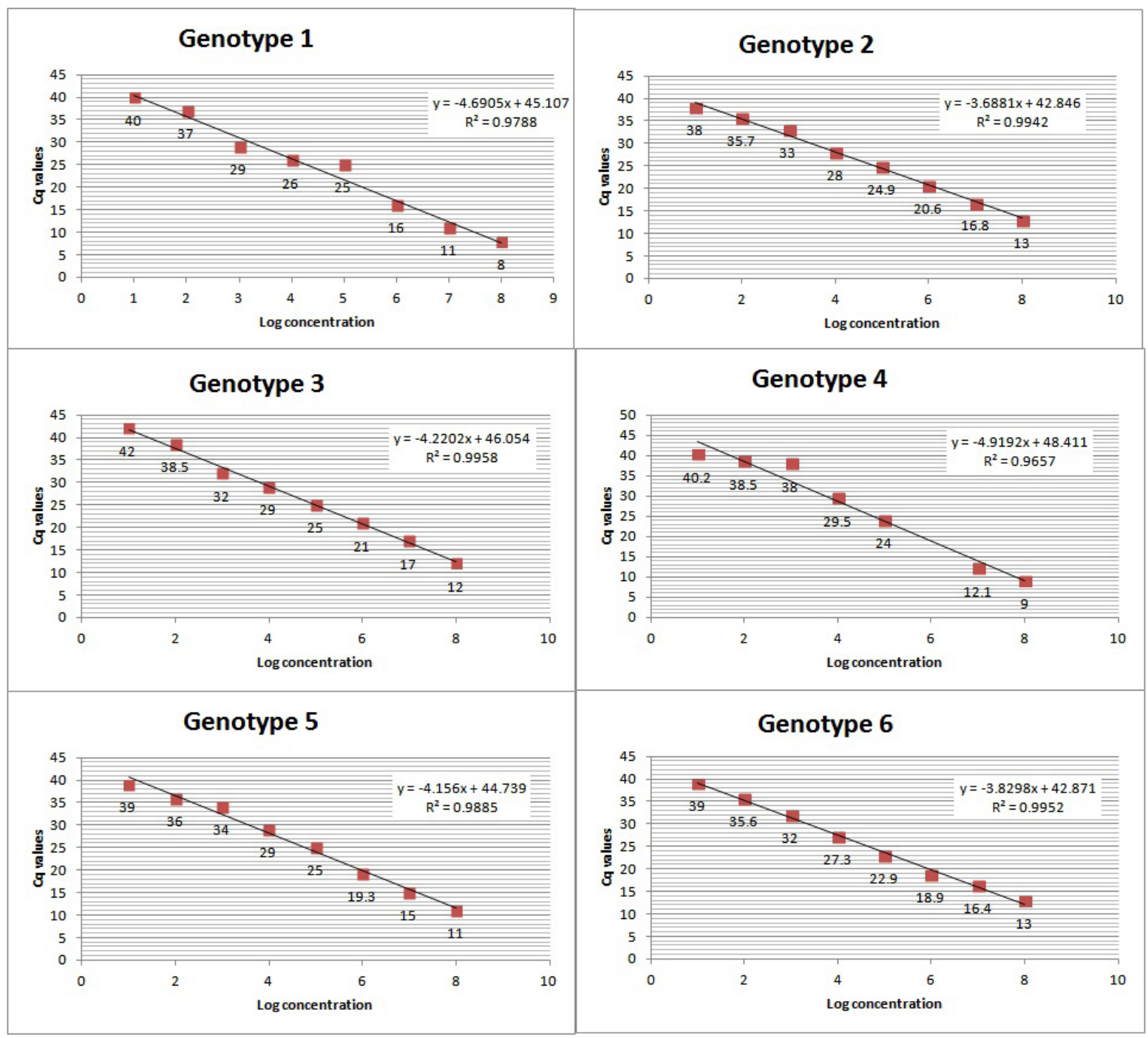

Figure 1: Standard curves showing amplification plots for HCV genotypes 1-6 using standard cloned plasmids. These standard curves were generated from amplification plots run in triplicates and showing linearity up to an $8 \log _{10}$ dynamic range. The correlation coefficient and the slope of each standard plot are shown individually. 
On regression analysis, the values of correlation coefficient $\left(\mathrm{R}^{2}\right.$ value) and $\mathrm{y}$-intercept were calculated for different genotypes and found to be 0.9788 and 45.107 for genotype-1, 0.9942 and 42.846 for genotype-2, 0.9958 and 46.054 for genotype-3, 0.9657 and 48.411 for genotype-4, 0.9885 and 44.739 for genotype-5, 0.9952 and 42.871 for genotype-6, respectively. Each standard curve was generated from the amplification plots run in triplicate and showed linearity up to an $8-\log _{10}$ dynamic range. The $\mathrm{Cq}$ values, termed as quantification cycle and indicating minimum cycle number showing amplification of a particular genome, were used to determine the copy number of ssDNA from genotype-1 to genotype- 6 using following formula:

\section{RNA copy $=6.023 \times 10^{23}($ copy $/ \mathrm{mol}) \times$ DNA amount (g) / DNA length $(\mathrm{bp}) \times 330(\mathrm{~g} / \mathrm{mol} / \mathrm{bp})$}

The results from the above study indicated the mean $\mathrm{Cq}$ value to be 24 for genotype-1, 25.5 for genotype-2, 27 for genotype-3, 27 for genotype-4, 25 for genotype-5 and 26 for genotype- 6 , respectively. The lower limit of detection (LOD) using control plasmid was found to be 176 copies $/ \mathrm{mL}$ for genotypes $1,2 \& 3$ and 167 copies $/ \mathrm{mL}$ for genotypes 4, $5 \& 6$, respectively (Table 3 ). The dynamic range for all singleplex assays was found to be $10^{1}$ to $10^{8}$ DNA plasmid copies per microliter. The concentration of DNA plasmid beyond this range could not show Cq values in the desired range of $10-35$ cycles. This demonstrates that the DNA plasmid used in all our standard curves falls in a range suitable for computing possible $\mathrm{Cq}$ values for genotypes 1 to 6 .

The sensitivity check of singleplex assay was done using sera samples positive for different genotypes, as confirmed by the sequence analysis. Using sera from 239 patients with different types of liver diseases, HCV-RNA was detected in 98 cases. These HCV-RNA positive sera were analyzed for HCV genotypes. The sensitivity was found to be $94.89 \%$ for a total number of 98 samples used. Individually, the sensitivity was found to be $83.87 \%$ for genotype- $1,92.85 \%$ for genotype- 3 and $28.57 \%$ for genotype- 4 . Genotypes 2,5 and 6 could not be detected in these sera samples. Similarly, the specificity of singleplex was also assessed using sequence based HCV genotyping as a gold standard. The results demonstrated $100 \%$ specificity for the number of sera analyzed. In order to find out the impact of serum on amplification, plasmid template was added to sera samples followed by amplification under similar set of experimental conditions and using two different concentrations of the template. The results demonstrated that amplification remains unaffected with the presence or absence of serum used in reaction mixture while doing amplification. Attempts were made to also determine the specificity of probes. The amplified products were analyzed by dual color analysis at different wavelength. Fluorescence was found to be intense for a specific dye in a particular channel. This was noted in the case of all genotypes.

After standardization of singleplex assay for each genotype, the experimental protocol was designed for multiplex assay using similar optimum conditions. It is important to mention here that multiplex for six genotypes of HCV cannot be conducted in a single tube LightCycler 2.0 (Roche, Germany). For this limitation of the equipment, the multiplex system was developed as a two reaction sets procedure: first set was used for simultaneous detection of genotypes 2, 3, 4 and 5, and the second set for genotypes 1 and 6 . Both these sets were run simultaneously under similar conditions of amplification. The amplification curves obtained in these two sets of multiplex assays using standard plasmid are shown in Figure 2 (a-d) and Figure $3(a-b)$. Figure 2(a) shows the sigmoid amplification curve for genotype-3 at $560 \mathrm{~nm}$. When the channel was changed to $610 \mathrm{~nm}$, there appeared amplification curve for genotype-2 as shown in Figure 2(b). Similarly, 640 $\mathrm{nm}$ produced sigmoid amplification curve for genotype-4 [Figure 2(c)], $705 \mathrm{~nm}$ for genotype- 5 [Figure 2(d)], 530 $\mathrm{nm}$ for genotype-1 Figure $3(\mathrm{a})$, and $670 \mathrm{~nm}$ for genotype- 6 [Figure 3(b)]. Straight lines in all amplification curves indicate negative control.

\begin{tabular}{|c|c|c|c|c|c|c|c|}
\hline \multirow[b]{2}{*}{ Genotype } & \multirow{2}{*}{ Copy number $(\mathrm{mol} / \mu \mathrm{L})$} & \multirow{2}{*}{$\begin{array}{l}\text { Singleplex } \\
\text { Ca values }\end{array}$} & \multicolumn{5}{|c|}{ Multiplex } \\
\hline & & & Mean $\mathrm{Cq}$ value & LOD (copies/ $\mu$ L) & Cq values & Mean $\mathrm{Cq}$ value & LOD (copies/ $\mu \mathrm{L}$ ) \\
\hline$\overline{\text { G1 }}$ & $1.76 \times 10^{8}-1.76 \times 10^{1}$ & $<8-40$ & 24 & 176 & $<11-42$ & 24.65 & 176 \\
\hline G2 & $1.76 \times 10^{8}-1.76 \times 10^{1}$ & $<13-38$ & 25.5 & 176 & $<17.2-39$ & 28.1 & 176 \\
\hline G3 & $1.76 \times 10^{8}-1.76 \times 10^{1}$ & $<12-42$ & 27 & 176 & $<8.6-42$ & 25.3 & 176 \\
\hline G4 & $1.67 \times 10^{8}-1.67 \times 10^{1}$ & $<9-40.2$ & 24.6 & 167 & $<9.1-40.2$ & 24.65 & 167 \\
\hline G5 & $1.67 \times 10^{8}-1.67 \times 10^{1}$ & $<11-39$ & 25 & 167 & $<12.3-39$ & 25.65 & 167 \\
\hline G6 & $1.67 \times 10^{8}-1.67 \times 10^{1}$ & $<13-39$ & 26 & 167 & $<15.4-40$ & 27.75 & 167 \\
\hline
\end{tabular}

The mean was calculated for standards by repeating in duplicate.

The copy number of standard was calculated by formula cDNA copy $=\left[6.02 \times 10^{23}(\mathrm{copy} / \mathrm{mol}) \times \mathrm{cDNA}\right.$ amount $\left.(\mathrm{g})\right] /[\mathrm{cDNA}$ length $(\mathrm{bp}) \times 330(\mathrm{~g} / \mathrm{mol} / \mathrm{bp})]$. 
a

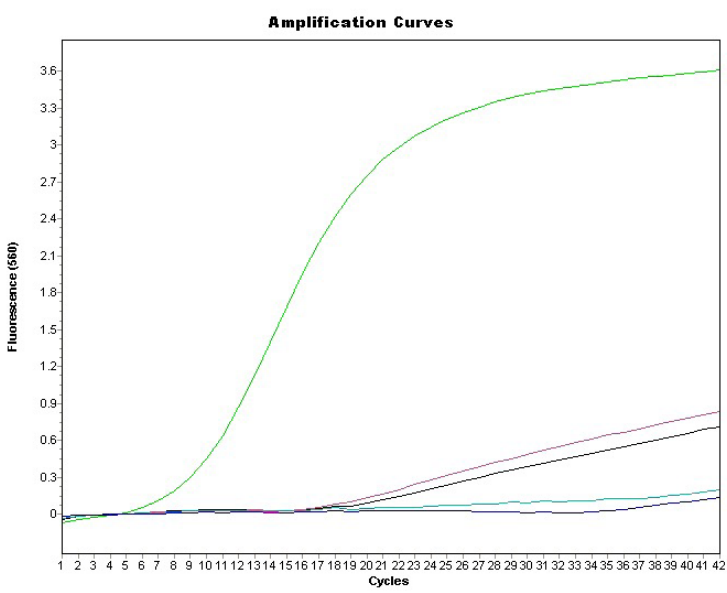

c

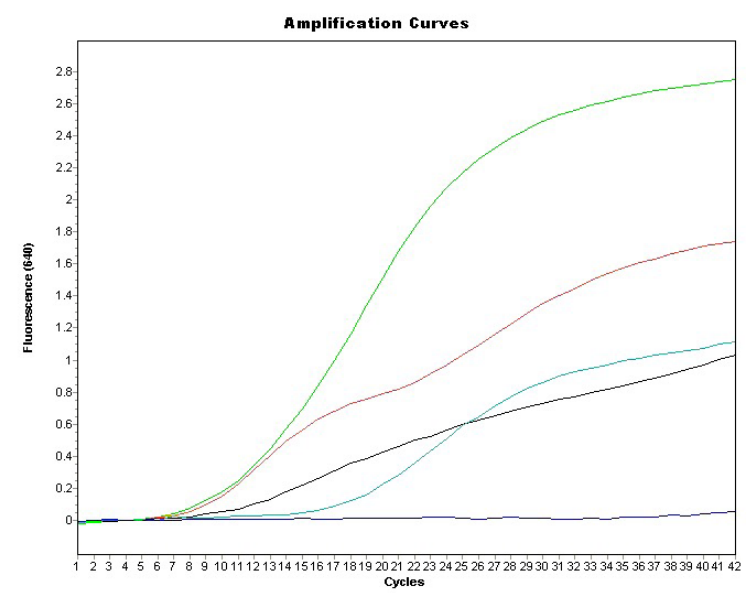

b

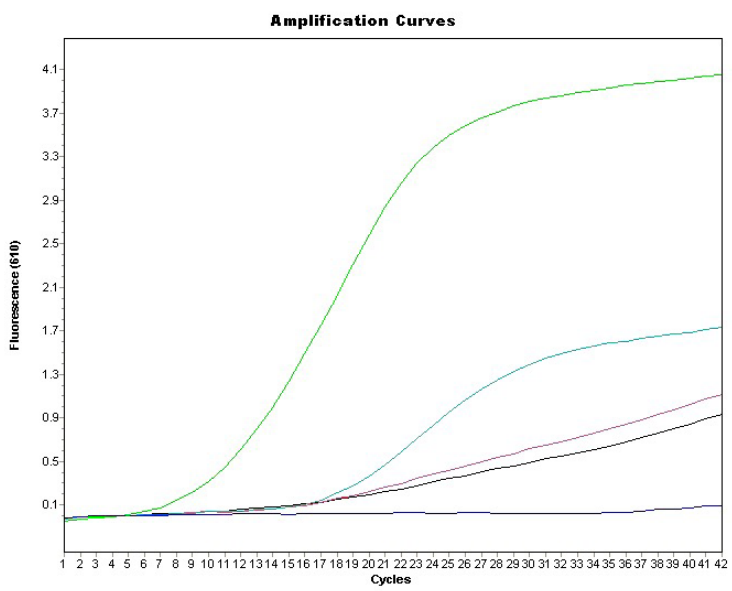

d

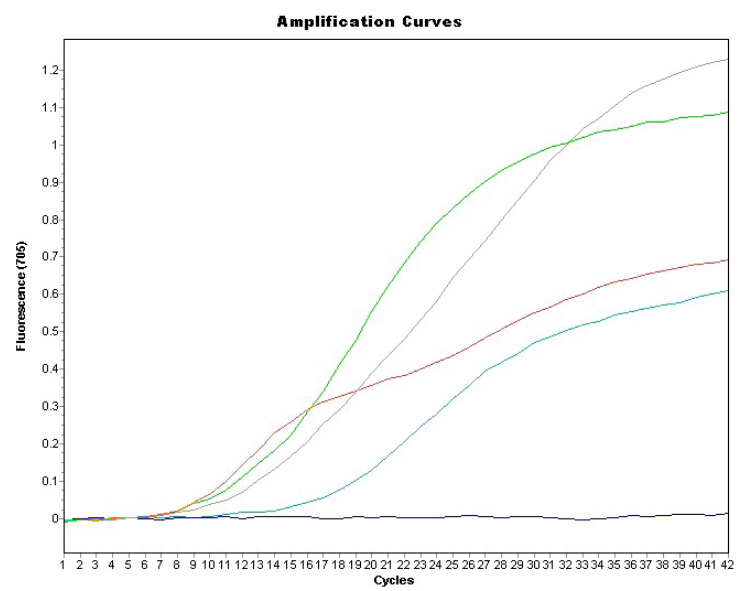

Figure 2: Amplification curves obtained by Multiplex qPCR for set-one comprising of genotype 2, 3, 4 and 5 using standard plasmid (108 ${ }^{8}$ copies/ $\left.\mu \mathrm{L}\right)$. The X-axis depicts quantification cycle ( $\mathrm{Cq}$ ) and $\mathrm{Y}$-axis depicts fluorescence level (RFU). Straight line indicates absence of amplification. (a) green curve shows amplification of genotype-3 at $560 \mathrm{~nm}$; (b) red curve shows amplification of genotype-2 at $610 \mathrm{~nm}$; (c) blue curve shows amplification of genotype-4 at $640 \mathrm{~nm}$; (d) black curve shows amplification of genotype-5 at $705 \mathrm{~nm}$.

a

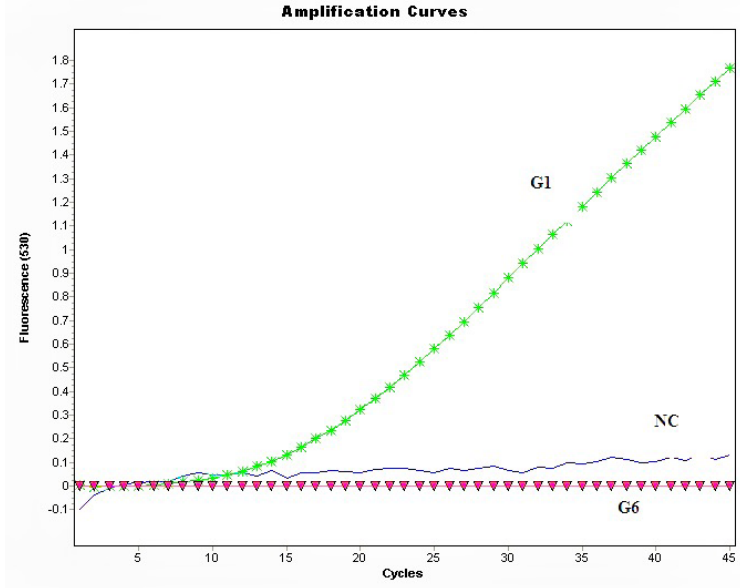

$\mathrm{b}$

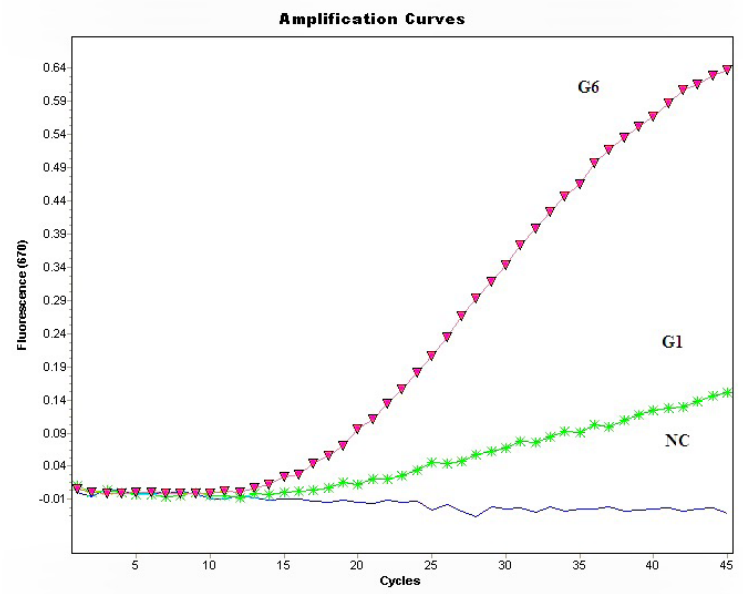

Figure 3: Amplification curves obtained by Multiplex qPCR for set-two comprising of genotype 1 and 6 using standard plasmid as template with concentration of $10^{8}$ copies/ $\mu \mathrm{L}$. The X-axis depicts quantification cycle (Cq) and $\mathrm{Y}$-axis depicts fluorescence level (RFU). Straight line indicates absence of amplification. (a) green [star] curve shows amplification of genotype-1 at $530 \mathrm{~nm}$, (b) red [triangle] curve shows amplification of genotype- 6 at $670 \mathrm{~nm}$. 
Multiplex qPCR assay demonstrated the mean Cq values to be 24.65 for genotype-1, 28.1 for genotype-2, 25.3 for genotype-3, 24.65 for genotype-4, 25.65 for genotype- 5 and 27.75 for genotype- 6 . These values are shown in Table 3. Similarly, the lower LOD values in singleplex as well as multiplex assays were found to be comparable for all the genotypes indicating no change in LOD, while evolving singleplex into multiplex assay (Table 3). Another observation made was that the mean $\mathrm{Cq}$ values for template concentration of $10^{1}$ copies $/ \mu \mathrm{L}$ for all genotypes were found to be more than 35 cycles. However, the $\mathrm{Cq}$ value was noted at 35 cycles for template concentration of $10^{2}$ copies $/ \mu \mathrm{L}$ for these genotypes. Since $\mathrm{Cq}$ value at $10^{1}$ copies $/ \mu \mathrm{L}$ is greater than the prescribed and acceptable range of 10-35 cycles, this lower concentration of template (i.e., $10^{1}$ copies $/ \mathrm{mL}$ ) was abandoned for use in multiplex assay, finally recognizing that the concentration of $10^{2}$ copies $/ \mu \mathrm{L}$ was accepted for the multiplex assay.

In order to validate the findings on HCV genotypes using our newly developed multiplex real time PCR, a comparison of genotyping by multiplex was also made with sequence analysis using the same set of samples. The core region of HCV genome was used as the target region for comparison. Twenty patients' sera were selected for direct sequencing by commercial firms. In all these cases, 399 bp target region of HCV-core was amplified using conventional PCR, and then purified for sequencing; this was followed by BLAST analysis and multiple alignments of sequences were done to determine the genotype of HCV. We observed a 100\% coherence in results obtained on genotyping using multiplex real time PCR and sequence analysis.

To assess the use of this multiplex qPCR assay, a total of 98 patients' sera positive for HCV-RNA were analyzed by multiplex assay under the conditions given above. The results obtained demonstrated the presence of genotype-1 in 26 cases $(26.53 \%)$, genotype- 3 in 65 cases $(66.32 \%)$, and genotype- 4 in 2 cases $(2.04 \%)$. None of these sera could show the presence of genotypes 2, 5 and 6. Moreover, 1 out of 98 cases carried the presence of genotypes 1 and 3 indicating a mixed infection of two genotypes. A total of 5 sera samples could not show the presence of any genotype.

For comparison of multiplex qPCR results with other conventional assays, we conducted RFLP using the same set of sera. The results demonstrated that cases reported negative by RFLP were picked up by multiplex. Moreover, the RFLP was unable to detect genotype- 4 in two cases and mistyped in another two cases. This demonstrated qPCR to be superior to RFLP.

\section{DISCUSSION}

HCV is not a single molecular entity, rather it represents numerous molecular species. Based on variation in sub genomic region of HCV genome, ${ }^{[20]}$ it has been classified in to six major genotypes and more than hundred isotypes. ${ }^{[21]}$ The genotypes of HCV have been named as genotype 1 to 6 . These genotypes are reported to differ not only in their pathogenicity during HCV infection, but also in response to antiviral therapy. ${ }^{[22]}$ Whereas genotype 1 and 3 respond well to the treatment and get eradicated during the therapy, genotype 2 and 4 are difficult to be affected by antiviral agents. ${ }^{[23]}$ This appeals to not only an early detection of $\mathrm{HCV}$ infection, but also the exact determination of $\mathrm{HCV}$ genotypes before planning a therapeutic strategy against this infection.

Earlier studies reported few assays which were used to determine HCV genotypes in human sera. These methods include PCR based assays, ${ }^{[13,14]}$ Line probe assays, ${ }^{[12]}$ RFLP assays ${ }^{[9,10]}$ and sequence analysis. In all these assays, sequence analysis was considered to be more reliable and used as the gold standard method. However, the demerit of sequence analysis based assays are their high cost and non-availability in most of the laboratories. Since HCV genotyping is a prime need of each hepatology unit, it is important that simple and reliable assays for genotyping are available in all the centers dealing with liver problems. The present study was planned with an aim to develop a sensitive multiplex real time PCR to conduct HCV genotyping in patients' sera. The study described here gives a detail of standardization of multiplex assay and its application in sera for HCV genotype determination in patient with different liver diseases.

A major problem faced in designing real time PCR for HCV genotyping is the high genetic variability among genotypes and subtypes in the non-coding region (UTR) of HCV genome. Another issue in designing multiplex real time PCR assay for HCV genotyping arises since there are only few nucleotide differences between the genotypes and so, it is a difficult task to obtain one set of primers and probe sequences to detect a particular genotype. Of course, UTR comprises conserved regions and the genotypes may be distinguished by the unique sequences in these regions. ${ }^{[24,25]}$ Moreover, some recent studies have reported that the core and NS5b regions are endowed with the sequence diversity for the generation of genotype-specific primers. ${ }^{\left[{ }^{[6]}\right.}$ Therefore, it was planned to use these regions as possible targets to develop primers and probes for HCV genotypes by qPCR.

It is worth to describe here that a singleplex assay for each individual HCV genotype was standardized before 
developing the multiplex assay using genotype specific primers and probes. Also, different sub genomic regions of HCV genome were used to develop assays for different genotypes (Table 1). Genotype specific nucleotide sequence were selected from 5' UTR, core and NS5b regions of HCV genome. ${ }^{[27]}$ Since, 5' UTR is not heterogeneous enough for its use in the determination of HCV subtypes of genotypes 2 and $4,{ }^{[21]}$ the core region was preferred for the detection of these genotypes. NS5b was used due to the presence of specific variations in its sequence for different genotypes. ${ }^{[28-30]}$ The reporter dyes for Taqman chemistry based assays were selected according to the available emission filters. Previous studies have reported sensitive real time assays for quantitative detection of $\mathrm{HCV}$ when using FAM, HEX, etc., as reporter dyes. ${ }^{[31]}$ On this basis, the present study included FAM as a reporter dye and demonstrated the considerable improvement in the reproducibility of results. For optimization of the multiplex assay, the primer concentrations were often used in 1 to $4 \mu \mathrm{M}$ and all probes in 1 to $2 \mu \mathrm{M}$ concentrations. All TaqMan probes were labeled with Black Hole Quencher (BHQ) as quencher dye, on the lines reported in various other studies. ${ }^{[32,33]} \mathrm{Cook}$ et al. ${ }^{[28]}$ also reported a multiplex real-time RT-PCR assay for the simultaneous detection and subtyping of HCV. This procedure has a support from various other studies developed elsewhere. ${ }^{[28,34]}$

The results of multiplex qPCR were quite encouraging and showed a prospect of solutions to several problems. It is important to note here that multiplex developed in the present study was divided in two sets: in set-one, there was simultaneous detection of genotypes 2, 3, 4 and 5, whereas in set-two, genotypes 1 and 6 were detected under similar conditions. An attempt was made to validate the results of this newly developed multiplex assay by comparing its results on genotyping with those obtained by sequence analysis also. When the results from these two assays were compared, we found a $100 \%$ coherence between the two. This not only points towards high sensitivity of multiplex assay but also presents the development of an easily available technique for its possible use in all the routine laboratories of liver centers.

Present assay shows a lower LOD to be $100-200 \mathrm{IU} / \mathrm{mL}$ for all the genotypes. This is in contrast to the study by Nakatani et al. ${ }^{[35]}$ who reported the limit to be 125 - $500 \mathrm{IU} /$ $\mathrm{mL}$. The current genotyping method presented an overall detection rate of 93 out of $98(94.89 \%)$ patients included in this study. This is nearly similar to the previously reported PCR-based methods ${ }^{[2]}$ for genotyping. Multiplexing usually loses sensitivity and has a negative impact on the specificity as compared to singleplex, as observed in other studies. ${ }^{[32]}$ However, the results of present multiplexing were very interesting. We observed that $\mathrm{Cq}$ values of multiplex could not show a significant difference from the value obtained in singleplex assays for each genotype. Our findings get support from previous reports that demonstrated an advantage of multiplex assay and its superiority over other available assays including the conventional PCR, RFLP and sequence analysis. ${ }^{[28,32,36]}$ These studies report that real-time qPCR assay can detect HCV genotypes in all the samples reported negative by sequencing and RFLP. This shows multiplex qPCR to be more sensitive as compared to other assays. Cook et al. ${ }^{[28]}$ also compared the real-time assay with RFLP and sequencing methods and found superiority of multiplex assay over RFLP and sequencing assays.

In conclusion, the present study describes the standardization of a multiplexing qPCR for its use in determination of $\mathrm{HCV}$ variants in sera from patients. The results of this study demonstrated that multiplex PCR is possible and produces results for determining the HCV-genotypes in a single step procedure and minimum possible time. Since, all the genotypes do not show similar response to anti-viral treatment, ${ }^{[11]}$ it becomes even more essential for clinical practitioners to know the status of $\mathrm{HCV}$-genotypes before planning the strategy for treatment. The patients found with non-responder HCV genotypes have to be dealt with separately. This not only saves time for laboratory procedures but also helps clinical practitioners in having results for an early decision on disease management. Several other methods have been attempted for HCV genotyping earlier, however, this assay appears to be more prompt, promising and specific.

\section{Conflict of Interest}

There is no conflict of interest among the authors.

\section{REFERENCES}

1. Lavanchy D. The global burden of hepatitis C. Liver Int 2009; 29 Suppl 1: 74-81.

2. Prieto M, Berenguer M, Rimola A, Loinaz C, Barrios C, Clemente G, et al. Liver transplantation in hepatitis C: a Spanish multicenter experience. Eur J Gastroenterol Hepatol 1998; 10: 771-76.

3. Choo QL, Kuo G, Weiner AJ, Overby LR, Bradley DW, Houghton M. Isolation of a cDNA clone derived from a blood-borne non-A, non-B viral hepatitis genome. Science 1989; 244: 359-62.

4. Moradpour D, Penin F, Rice CM. Replication of hepatitis C virus. Nat Rev Micro 2007; 5: 453-63.

5. Irshad M, Khushboo I, Singh S, Singh S. Hepatitis C virus (HCV): A review of immunological aspects. Int Rev Immunol 2008; 27: 497-517.

6. Okamoto H, Sugiyama Y, Okada S, Kurai K, Akahane Y, Sugai Y, Tanaka $\mathrm{T}$, et al. Typing hepatitis $\mathrm{C}$ virus by polymerase chain reaction with typespecific primers: application to clinical surveys and tracing infectious sources. J Gen Virol 1992; 73: 673-79.

7. Ohno T, Lau JY. The "gold-standard," accuracy, and the current concepts: hepatitis C virus genotype and viremia. Hepatology 1996; 24: 1312-15.

8. Schroter M, Feucht HH, Schafer P, Zöllner B, Laufs R. Serological determination of hepatitis $C$ virus subtypes 1a, 1b, 2a, 2b, 3a and 4a by 
a recombinant immunoblot assay. J Clin Microbiol 1999; 37: 2576-80.

9. Park YS, Lee KO, Oh MJ, Chai YG. Distribution of genotypes in the 5' untranslated region of hepatitis C virus in Korea. J Med Microbiol 1998; 47: 643-47.

10. Theirs V, Jaffredo F, Chodan N, Brechot C. Development of a simple restriction fragment length polymorphism (RFLP) based assay for HCV genotyping and serotyping. J Virol Methods 1997; 65: 9-17.

11. Nguyen MH, Keeffe EB. Prevalence and treatment of hepatitis $C$ virus genotypes 4, 5, and 6. Clin Gastro Hep 2005; 3: S97-101.

12. Cai Q, Zhao Z, Liu Y, Shao X, Gao Z. Comparison of three different HCV genotyping methods: core, NS5B sequence analysis and line probe assay. Int J Mol Med 2013; 31: 347-52.

13. Lindh $M$, Hannoun C. Genotyping of hepatitis $C$ virus by Taqman realtime PCR. J Clin Virol 2005; 34: 108-14.

14. Rolfe KJ, Alexander GJ, Wreghitt TG, Parmar S, Jalal H, Curran MD. A real-time Taqman method for hepatitis $\mathrm{C}$ virus genotyping. J Clin Virol 2005; 34: 115-21.

15. Irshad M, Ansari MA, Irshad K, Lingaiah R. Novel single-step multiplex real-time polymerase chain reaction assay for simultaneous quantification of hepatitis virus A, B, C, and E in serum. J Gastroenterol Hepatol 2013; 28: 1869-76.

16. Benson DA, KarschMizrachi I, Lipmann DJ, Ostell K, Wheeler DL. Genbank. Nucleic Acids Res 2006; 34: D16-20.

17. Thompson JD, Higgins DG, Gibson TJ. Clustal W. Improving the sensitivity of progressive multiple sequence alignment through sequence weighting, positions-specific gap penalties and weight matrix choice. Nucleic Acids Res 1994; 22: 4673-80.

18. Chinchai T, Labout J, Noppornpanth S, Theamboonlers A, Haagmans BL, Osterhaus AD, Poovorawan Y. Comparative study of different methods to genotype hepatitis $C$ virus type 6 variants. J Virol Methods 2003; 109: 195-201.

19. McOmish F, Yap PL, Dow BC, Follett EAC, Seed C, Kellar AJ, Cobain TJ, et al. Geographical distribution of different hepatitis $\mathrm{C}$ virus genotypes in blood donors: An international collaborative survey. J Clin Microbiol 1994; 32: 884-92.

20. Kato N. Molecular virology of hepatitis C virus. Acta Med Okayama 2001; 55: 133-59.

21. Simmonds P, Mellor J, Sakuldamrongpanich T, Nuchaprayoon C, Tanprasert S, Holmes EC, Smith DB. Evolutionary analysis of variants of hepatitis $C$ virus found in South-East Asia: comparison with classifications based upon sequence similarity. J Gen Virol 1996; 77: 3013-24.

22. Sarrazin C, Hezode C, Zeuzem S, Pawlotsky JM. Antiviral strategies in hepatitis C virus infection. J Hepatol 2012; 56 Suppl 1: S88-100.

23. Mauss S, Berger F, Vogel M, Pfeiffer-Vornkahl H, Alshuth U, Rockstroh $\mathrm{J}$, et al. Treatment results of chronic hepatitis c genotype 5 and 6 infections in Germany. Zeitschriftfür Gastroenterologie 2012; 50: 441-44.
24. Chaudhary A, Kukreti H, Pasha ST, Gupta S, Kumari M, Khare S, et al. Impact of HIV on genomic variability in the 5'UTR of HCV in Indian patients with HCV/HIV co-infection. Intervirology 2008; 51: 224-29.

25. El Awady MK, Azzazy HM, Fahmy AM, Shawky SM, Badreldin NG, Yossef SS, et al. Positional effect of mutations in 5'UTR of hepatitis C virus 4a on patients' response to therapy. World J Gastroenterol 2009; 15: 1480-86.

26. Murphy DG, Willems B, Deschênes M, Hilzenrat N, Mousseau R, Sabbah $\mathrm{S}$. Use of sequence analysis of the NS5B region for routine genotyping of hepatitis $\mathrm{C}$ virus with reference to $\mathrm{C} / \mathrm{E} 1$ and 5 ' untranslated region sequences. J Clin Microbiol 2007; 45: 1102-12.

27. Qiu P, Cai X-Y, Ding W, Zhang Q, Norris ED, Greene JR. HCV genotyping using statistical classification approach. J Biomed Sc. 2009; 8: 16-62.

28. Cook L, Sullivan K, Krantz EM, Bagabag A, Jerome KR. Multiplex realtime reverse transcription-PCR assay for determination of hepatitis $c$ virus genotypes. J Clin Microbiol 2006; 44: 4149-56.

29. Martró E, González V, Buckton AJ, Saludes V, Fernández G, Matas L, et al. Evaluation of a new assay in comparison with reverse hybridization and sequencing methods for Hepatitis $\mathrm{C}$ virus genotyping targeting both 5 ' noncoding and nonstructural $5 \mathrm{~b}$ genomic regions. J Clin Microbiol 2008; 46: 192-97.

30. Enomoto N, Sakuma I, Asahina Y, Kurosaki M, Murakami T, Yamamoto $\mathrm{C}$, et al. Comparison of full-length sequences of interferon-sensitive and resistant hepatitis $C$ virus $1 \mathrm{~b}$ : sensitivity to interferon is conferred by amino acid substitutions in the NS5a region. J Clin Invest 1995; 96: 224-30.

31. Meng S, Li J. A novel duplex real-time reverse transcriptase-polymerase chain reaction assay for the detection of hepatitis C viral RNA with armored RNA as internal control. Virol J 2010; 7: 117.

32. Huber I, Campe H, Sebah D, Hartberger C, Konrad R, Bayer M, et al. A multiplex one-step real-time RT-PCR assay for influenza surveillance. Euro Surveill 2011; 17: 16(7).

33. Taranta A, Rogalska-Taranta M, Gutierrez R, Manns MP, Bock M, Wursthorn K. Rapid hepatitis B and hepatitis Delta virus RNA quantification from small-sized liver tissue samples. J Clin Virol 2014; 61: 286-88.

34. Engle RE, Russell RS, Purcell RH, Bukh J. Development of a TaqMan assay for the six major genotypes of hepatitis $\mathrm{C}$ virus: comparison with commercial assays. J Med Virol 2008; 80: 72-79.

35. Nakatani SM, Santos CA, Riediger IN, Krieger MA, Duarte CAB, Lacerda $\mathrm{MA}$, et al. Development of hepatitis $\mathrm{C}$ virus genotyping by real-time PCR based on the NS5B region. PLoS One 2010; 5: e10150.

36. Irshad M, Gupta P, Mankotia DS, Ansari MA. Multiplex qPCR for serodetection and serotyping of hepatitis viruses: A brief review. World J Gastroenterol 2016; 22: 4824-34.

How to cite this article: Singh A, Mankotia DS, Irshad M. A singlestep multiplex quantitative real time polymerase chain reaction assay for hepatitis C virus genotypes. J Transl Intern Med 2017; 5: 34-42. 